\title{
Parâmetros climáticos e variação de compostos fenólicos em cevada
}

\author{
Climatic parameters and variation of phenolic compounds in barley
}

\section{Aline Sobreira Bezerra ${ }^{\mathrm{I}^{*}}$ José Laerte Nörnberg ${ }^{\mathrm{I}}$ Fernanda Oliveira Lima ${ }^{\mathrm{II}}$ Marcelo Barcellos da Rosa ${ }^{\text {II }}$ Leandro Machado de Carvalho ${ }^{\text {II }}$}

\section{RESUMO}

Objetivou-se quantificar os compostos fenólicos em extrato hidroetanólico de grãos das cultivares de cevada ('BRS Lagoa' e 'MN 743') em dois anos consecutivos de cultivo (2005 e 2006), avaliando a influência dos fatores climáticos nesse conteúdo. Os compostos fenólicos totais foram quantificados pelo método de Folin-Ciocalteau e os teores de rutina e ácidos cafeico e ferúlico por CLAE em fase reversa. O conteúdo de compostos fenólicos totais variou de 0,97 a $1,59 \mathrm{mg} \mathrm{AG} \mathrm{g}^{-1}$ de cevada e os fatores climáticos durante o período de plantio e colheita influenciaram no conteúdo. Foram identificados e quantificados nessas cultivares rutina, ácido cafeico e ácido ferúlico. A avaliação dos fatores climáticos no conteúdo de compostos fenólicos em cevada é de grande interesse, visando a sua importância nutricional e recomendação de cultivares com conteúdos expressivos de compostos bioativos.

Palavras-chave: Hordeum vulgare L., antioxidantes, fatores climáticos.

\section{ABSTRACT}

This study aimed to quantify the phenolic compounds in hydroethanolic extract of cultivar seeds ('BRS Lagoa' and 'MN 743') in two consecutive years of cultivation (2005 and 2006) evaluating the influence of climatic factors in such content. The total phenolic compounds were quantified by Folin-Ciocalteau's method and the levels of rutin and caffeic and ferulic acids by HPLC in the reversed-phase. The concentration of total phenolic compounds ranged from 0.97 to $1.59 \mathrm{mg} \mathrm{GA} \mathrm{g^{-1 }}$ of barley and the climatic factors during the planting and harvesting influenced the barley content. Caffeic, rutin and ferulic acid were identified and quantified in these cultivars. Assessment of climatic factors on the content of phenolic compounds in barley is of great interest aiming for their nutritional importance and recommendations of cultivars with significant content of bioactive compounds.

Key words: Hordeum vulgare L., antioxidants, climatic factors.

\section{INTRODUÇÃO}

Atualmente, evidências indicam os radicais livres e outros oxidantes como grandes responsáveis por doenças degenerativas associadas ao envelhecimento, câncer, doenças cardiovasculares, entre outros. Todavia, o consumo de substâncias antioxidantes naturais na dieta diária pode produzir uma ação protetora efetiva contra os processos oxidativos gerados por esses compostos (DEGÁSPARI \& WASZCZYNSKYJ, 2004).

Das diversas classes de substâncias antioxidantes de ocorrência natural, os compostos fenólicos têm recebido muita atenção nos últimos anos, sobretudo por inibirem a peroxidação lipídica e a lipo-oxigenase in vitro (SOARES, 2002). Estes se enquadram em diversas categorias, como fenóis simples, ácidos fenólicos (derivados dos ácidos benzóico e cinâmico), cumarinas, flavonoides, estilbenos, taninos condensados e hidrolisáveis, lignanas e ligninas (NASCK \& SHAHIDI, 2004).

A inibição da peroxidação lipídica e a lipo-oxigenase desempenhadas por esses compostos têm um papel importante na neutralização ou no sequestro de radicais livres e na quelação de metais de

\footnotetext{
'Núcleo Integrado de Desenvolvimento em Análises Laboratoriais (NIDAL), Departamento de Ciência e Tecnologia dos Alimentos, Universidade Federal Santa Maria (UFSM), Santa Maria, RS, Brasil. E-mail: alinecelo@hotmail.com. *Autor para correspondência.

"Laboratório de Análises Químicas (LACHEM), Departamento de Química, UFSM, Santa Maria, RS, Brasil. 
transição, agindo tanto na etapa de iniciação como na propagação do processo oxidativo. Os intermediários formados pela ação dos antioxidantes fenólicos são relativamente estáveis, devido à ressonância do anel aromático presente na estrutura dessas substâncias (SOUSA et al., 2007).

Em grãos de cevada, têm sido identificados derivados dos ácidos hidroxibenzoico e hidroxicinâmico, como o ácido trans-ferúlico, encontrado em maior quantidade no grão, seguido dos ácidos p-cumarínico e vanílico (MC MURROUGH et al., 1992; SHAHIDI \& NACZK, 2003). Esses ácidos são conhecidos por atuarem como antioxidantes primários na recepção de radicais livres, interrompendo a reação em cadeia e encontram-se presentes na camada de aleurona e no endosperma do grão (GOUPY et al., 1999).

Em pesquisa recente, compostos fenólicos como a rutina, ácido cafeico, ácido ferúlico e miricetina, foram identificados e quantificados em diferentes cultivares de cevada brasileira (BEZERRA et al., 2009) por Cromatografia Líquida de Alta Eficiência (CLAE, do inglês HPLC). Conforme reportado por KNEKT et al. (2002) e RODRIGUES et al. (2003), esses compostos têm exercido efeito cardioprotetor, hipolipídico, hipotensivo, antiviral e anti-inflamatório.

Dessa forma, como parte do estudo sobre a identificação e quantificação dos fenólicos em cevada e considerando a importância desses compostos como antioxidantes naturais, o presente trabalho teve como objetivo quantificar e identificar compostos fenólicos pelos métodos de Folin-Ciocalteau e por CLAE em extrato hidroetanólico das variedades de cevada recomendadas para cultivo no Brasil, MN 743 e BRS Lagoa, cultivadas nos anos de 2005 e 2006, e avaliar a influência das condições climáticas (temperatura média do ar, índice pluviométrico e insolação) entre as épocas de plantio e colheita na quantificação dos fenólicos entre essas variedades.

\section{MATERIAL E MÉTODOS}

Para o experimento, foram utilizadas amostras de cevada (BRS Lagoa e MN 743), cultivadas no município de Ibiaçá/Rio Grande do Sul, nas safras de 2005 e 2006, em ensaio de campo coordenado pelo Centro de Pesquisa da Empresa Brasileira de Pesquisa Agropecuária (Embrapa) de Passo Fundo. O delineamento experimental utilizado foi em blocos inteiramente casualizados com três repetições. Os dados foram submetidos à análise de variância e as médias comparadas pelo teste Tukey a 5\% de probabilidade, utilizando o sistema para análise e separação de médias em experimentos agrícolas - SASM - Agri, versão 4 (GODOY, 2001). Os resultados foram expressos em média \pm desvio padrão.

Os grãos, previamente secos, foram triturados em micro-moinho modelo Marconi a $27.000 \mathrm{rpm}$ durante 40 segundos, a fim de se obter tamanho de partículas (menor que $1 \mathrm{~mm}$ ) apropriadas para as análises. As amostras foram armazenadas em sacos de polietileno, sendo devidamente identificadas e mantidas sob congelamento a $-18^{\circ} \mathrm{C}$ até o processo extrativo.

Para o preparo dos extratos, foram utilizados como solvente água destilada e etanol 95\% grau analítico. Acetonitrila $\left(\right.$ Tedia $^{\circledR}$ ) foi usada no preparo da fase móvel. A água usada nas análises cromatográficas foi água ultrapura (Milli-Q). Rutina, ácido ferúlico e ácido cafeico $\left(\operatorname{Sigma}^{\circledR}\right)$, em soluções contendo 5,0,10,0,15,0 mg L $\mathrm{m}^{-1} \mathrm{em}$ metanol, foram utilizados como padrões internos, na quantificação por adição de padrão, para minimizar o efeito de matriz. O reagente de Folin-Ciocalteau foi adquirido da Merck e o ácido gálico da Vetec ${ }^{\circledR}$.

Os extratos foram preparados em concentrações de $12,5 \%(\mathrm{~m} / \mathrm{v})$ de farinha de cevada misturada em uma solução hidroetanólica (20:80, v/v). A mistura foi sonicada durante 30 minutos à temperatura ambiente, filtrada em filtro de papel $12,5 \mathrm{~mm}$ e em acetato de celulose $0,45 \mathrm{~mm}$ para injeção. Os extratos foram mantidos a $-5^{\circ} \mathrm{C}$ até o momento da análise. Essa condição experimental foi previamente avaliada (BEZERRA et al., 2009).

Adeterminação de fenóis totais foi realizada pelo método de Folin-Ciocalteau, segundo SOUSA et al. (2007), com modificações. As medidas de absorção foram realizadas por meio de espectroscopia na região do visível, utilizando espectrofotômetro Hewlett Packard (HP) UV-Vis com arranjo de diodos $(\lambda$ : $740 \mathrm{~nm}$ ). O teor de fenóis totais (FT) foi determinado por interpolação da absorbância das amostras contra uma curva de calibração construída com padrões de ácido gálico e expressa como mg de ácido gálico por grama de cevada (mg AG/g).

As análises de identificação e quantificação foram realizadas por Cromatografia Líquida de Alta Eficiência (CLAE), com cromatógrafo Dionex, acoplado com detector UV-Vis (UVD 170U). O software Chromeleon, versão 1997, foi usado para registrar os cromatogramas e medir as áreas dos picos. A separação dos fenólicos foi realizada em fase reversa em coluna $\mathrm{C} 18(4,6 \mathrm{mmx} 150 \mathrm{mmx} 5 \mu \mathrm{m})$. Os solventes foram degaseificados em banho ultrass $\tau$ nico 
(Ultrasonic Cleaner Unique ${ }^{\circledR}$ ). A cromatografia foi realizada à temperatura de $25^{\circ} \mathrm{C} \pm 1^{\circ} \mathrm{C}$ em eluição isocrática (acetonitrila e água deionizada (30:70, $\mathrm{v} / \mathrm{v})), \mathrm{pH} 4,0 \pm 0,5$ e fluxo de $0,5 \mathrm{~mL} \mathrm{~min}^{-1}$. Alíquotas de $20 \mu \mathrm{L}$ das amostras foram injetadas e a detec dos picos foi registrada em $254 \mathrm{~nm}$. O tempo de análise foi otimizado em 15 minutos.

\section{RESULTADOS E DISCUSSÃO}

Para análise e comparação dos resultados, foram utilizados dados disponibilizados pela Embrapa Trigo de Passo Fundo (2008) que mostraram que, nos anos de 2005 e 2006, a insolação em horas durante a época do plantio até a colheita da cevada (junho a outubro) foi em média 839,0 horas em 2005 e 982,6 horas em 2006. A precipitação pluvial média foi de $1029,7 \mathrm{~mm}$ em 2005 e 655,3mm em 2006 e a temperatura média do ar de $14,58^{\circ} \mathrm{C}$ em 2005 e $15,48^{\circ} \mathrm{C}$ em 2006.

Entre as cultivares analisadas, foram observados os menores teores médios significativos de fenólicos totais (FT) na safra de 2006 e, em 2005, os maiores teores médios quantificados (Tabela 1). Na análise por CLAE-UV, pôde-se identificar e quantificar os seguintes compostos nesta ordem de eluição: rutina>ácido cafeico>ácido ferúlico. Observou-se um maior teor médio significativo de rutina e de ácido cafeico na cultivar ' $\mathrm{MN} 743$ ' de 2005 e de 2006, respectivamente (Tabela 1). O ácido ferúlico foi quantificado em pequena quantidade somente na cultivar 'BRS Lagoa' (2006) em uma concentração de $0,80 \pm 0,27 \mathrm{mg} \mathrm{kg}^{-1}$. A separação cromatográfica dos compostos analisados e o perfil cromatográfico das cultivares pode ser observado na figura 1 .

De acordo com CARVALHO et al. (2004), os compostos fenólicos são instáveis e facilmente oxidáveis. Os derivados do ácido cinâmico, como, por exemplo, o ácido ferúlico, podem se isomerizar em solução aquosa sob influência de luz UV. Esse fato, assim como o método extrativo aplicado e variações de genótipos, pode explicar a razão da baixa quantificação do ácido ferúlico nas cultivares analisadas, tendo em vista que, este seria o composto encontrado em maior quantidade em grãos de cevada (MAILLARD \& BERSET, 1995). Com relação à variação química de plantas da mesma espécie, parâmetros como clima, radiação solar, nutrição mineral, entre outros, podem também interferir no conteúdo de praticamente todas as classes de metabólitos secundários como os flavonoides e ácidos fenólicos, conforme reportado por SANTOS \& BLATT (1998).

As baixas temperaturas têm influências significantes nos níveis de metabólitos secundários e uma correlação positiva tem sido relatada entre a intensidade e a duração do frio imposto ao milho (Zea mays) e a abundância de antocianinas e mRNA (CHRISTIE et al., 1994). A cevada, por exemplo, é uma gramínea cerealífera típica de clima que se adapta bem em temperaturas extremas e, conforme mostra a figura 2, uma maior concentração de fenóis totais foi observada em temperatura média mais baixa $\left(14,58^{\circ} \mathrm{C}\right)$.

Com relação à radiação ultravioleta, existe uma correlação positiva bem estabelecida entre intensidade de radiação solar e produção de compostos fenólicos (WATERMAN \& MOLE, 1994), tais como taninos (DUDT \& SHURE, 1994), antocianinas (JEONG et al., 2004), flavonoides (TATTINI et al., 2004), e isso pode ser explicado, principalmente no caso de flavonóides e fenilpropanóides correlatos, pela proteção contra a foto destruição proporcionada por esses metabólitos ao absorver e/ou dissipar a energia solar, dificultando assim a danificação dos tecidos mais internos pela radiação UV-B (WATERMAN \& MOLE,1994; GRACE \& LOGAN, 2000). Nas

Tabela 1 - Quantificação de compostos fenólicos* pelos métodos de Folin-Ciocalteau e CLAE-UV ( $\lambda: 254 \mathrm{~nm})$.

\begin{tabular}{|c|c|c|c|c|}
\hline Cultivares & Fenólicos totais ${ }^{\mathrm{A}}$ & Rutina $^{\mathrm{B}}$ & Ácido cafeico ${ }^{\mathrm{B}}$ & Ácido ferúlico ${ }^{\mathrm{B}}$ \\
\hline 'BRS Lagoa 2005' & $1,58 \pm 0,02^{\mathrm{a}}$ & $135,31 \pm 3,42^{b}$ & $24,88 \pm 6,81^{\mathrm{b}}$ & nd** \\
\hline 'BRS Lagoa 2006' & $1,02 \pm 0,01^{\mathrm{b}}$ & $48,81 \pm 4,36^{\mathrm{b}}$ & $13,39 \pm 1,17^{\mathrm{b}}$ & $0,80 \pm 0,27$ \\
\hline 'MN 743 2005' & $1,43 \pm 0,02^{\mathrm{a}}$ & $300,46 \pm 7,49^{\mathrm{a}}$ & $26,41 \pm 5,56^{\mathrm{b}}$ & nd \\
\hline 'MN 743 2006' & $0,97 \pm 0,02^{\mathrm{b}}$ & $100,27 \pm 5,03^{\mathrm{b}}$ & $50,29 \pm 3,57^{\mathrm{a}}$ & nd \\
\hline
\end{tabular}

\footnotetext{
*Valores médios com a mesma letra na mesma coluna não diferem significativamente entre si pelo teste de Tukey em nível de $5 \%$. nd**: não detectado.

${ }^{\mathrm{a}}$ Valores médios \pm desvio padrão expressos em $\mathrm{mg} \mathrm{AG} \mathrm{g}^{-1}$ de amostra.

${ }^{\mathrm{b}}$ Valores médios \pm desvio padrão expressos em $\mathrm{mg} \mathrm{kg}^{-1}$ de amostra.
} 


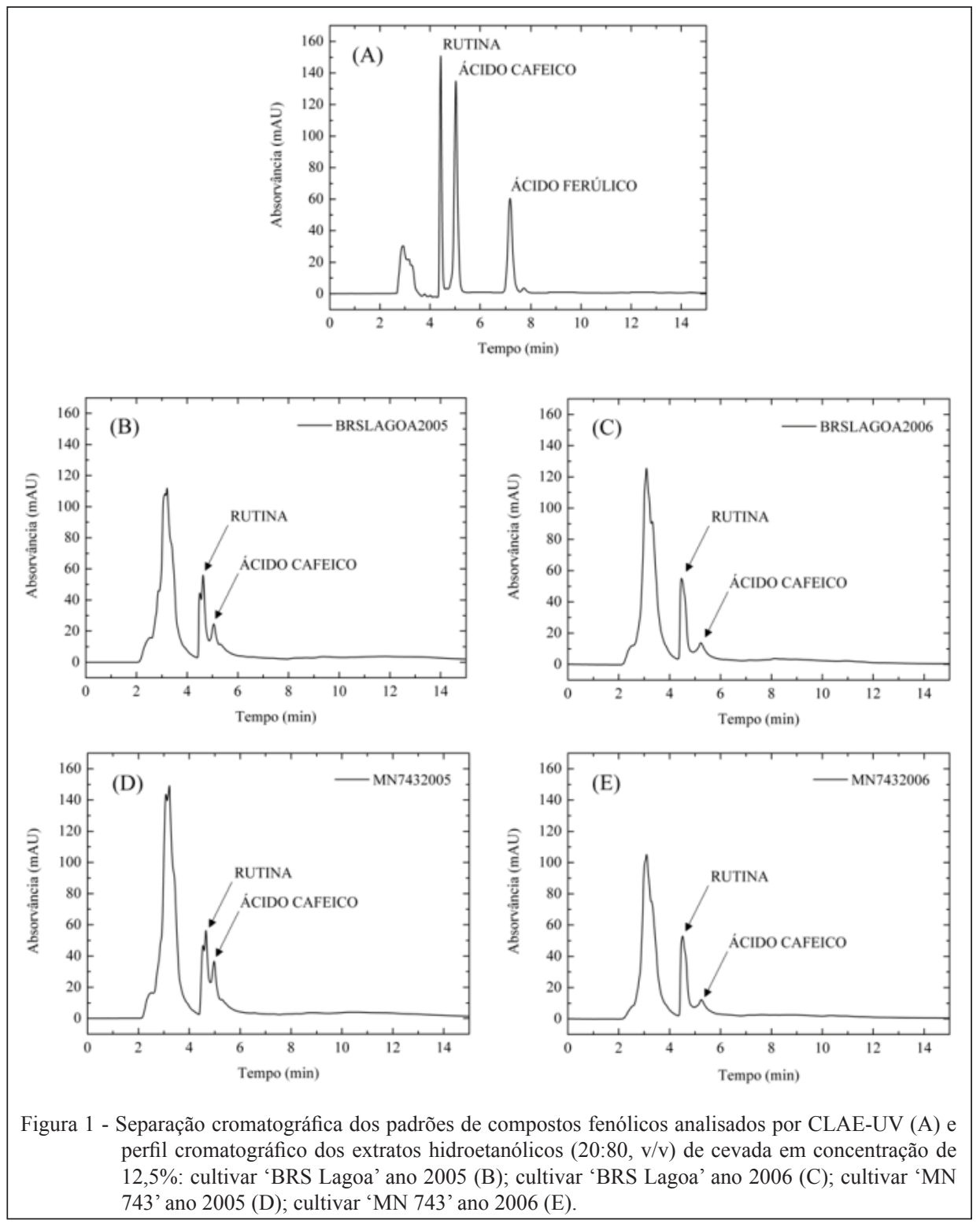

variedades de cevada analisadas, observou-se que uma maior insolação recebida pela planta, durante os períodos de plantio e colheita (982,6 horas), refletiu em uma menor concentração de fenóis totais, enquanto que uma menor insolação ( 839,0 horas) exibiu uma maior concentração de fenóis totais entre as variedades, como pode ser observado na figura 3 .

Os efeitos da chuva na vegetação também devem ser considerados, pois, conforme observado em estudos com Hypericum perforatum, houve um aumento significativo na concentração de flavonoides, hipericinas e ácido clorogênico nas flores sob condições de estresse hídrico; porém, com um decréscimo na concentração de hiperforinas (GRAY et al., 2003). O estresse hídrico frequentemente tem consequências significantes nas concentrações de metabólitos secundários em plantas e, conforme os autores, essa condição geralmente leva a um aumento na produção. Em cevada, foi observado, como mostra a figura 4 , que no ano 2005 , com maior índice pluviométrico no período de plantio e colheita, houve uma maior concentração de rutina, bem como de fenóis totais.

\section{CONCLUSÃO}

Considerando os resultados descritos pela literatura com outras plantas, porém inexistentes

Ciência Rural, v.43, n.9, set, 2013. 


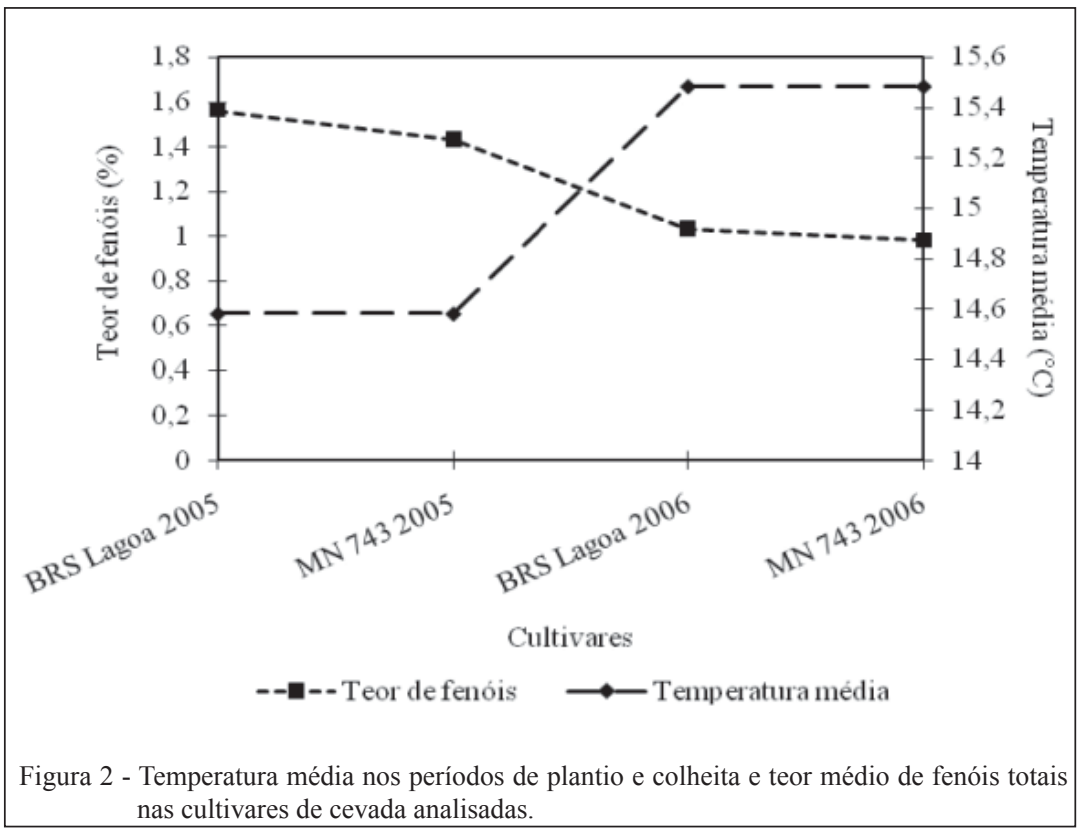

com cevada, e os observados neste trabalho, concluise que uma menor incidência solar, maior índice pluviométrico e uma menor temperatura média, foram considerados fatores favoráveis no aumento do conteúdo de fenólicos totais e de rutina nas cultivares de cevada de diferentes safras agrícolas.

A avaliação dos fatores climáticos no conteúdo de compostos fenólicos em cevada é de grande interesse, visando a sua importância nutricional e recomendação de cultivares com conteúdos expressivos de compostos bioativos.

\section{AGRADECIMENTOS E APRESENTAÇÃO}

Os autores agradecem ao Centro Nacional de Desenvolvimento Científico e Tecnológico $(\mathrm{CNPq})$, a Coordenação de Aperfeiçoamento de Pessoa de Nível Superior (CAPES) e a Fundação de Amparo a Pesquisa do Estado do Rio Grande do Sul (FAPERGS), pelas bolsas e auxílios concedidos, e ao Dr. Euclydes Minellla da Embrapa Trigo de Passo Fundo/RS, pelas amostras fornecidas para os estudos.

Este trabalho é parte da Dissertação de Mestrado apresentada pelo primeiro autor ao programa de Pós-graduação em Ciência e Tecnologia dos Alimentos da Universidade Federal de Santa Maria - UFSM, Santa Maria, RS, Brasil.

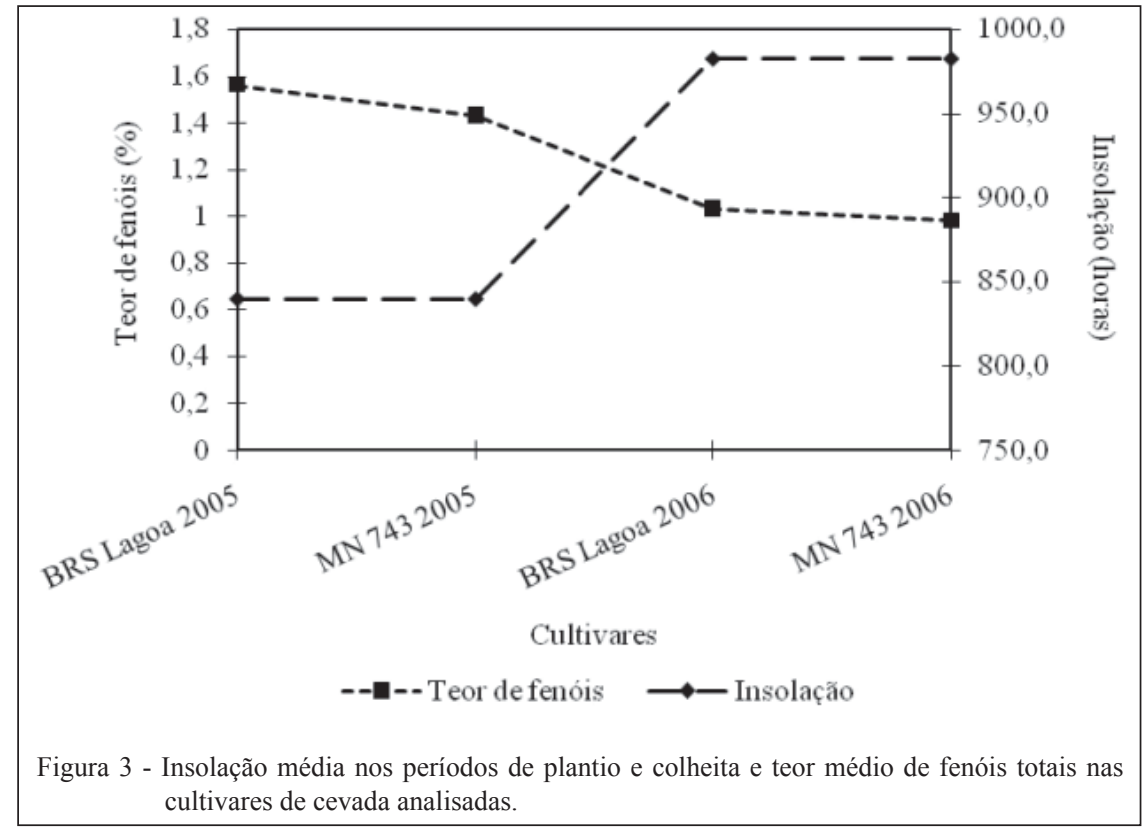

Ciência Rural, v.43, n.9, set, 2013. 


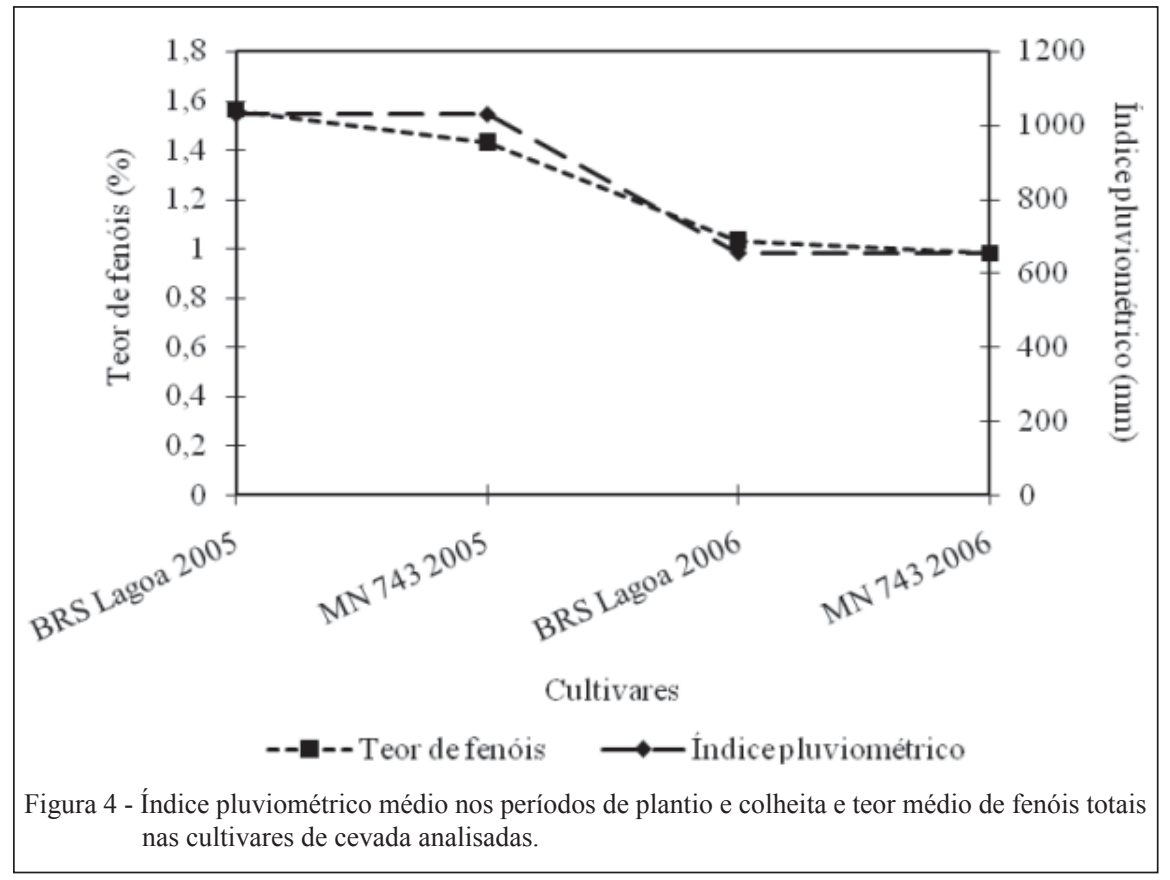

\section{REFERÊNCIAS}

BEZERRA, A.S. Caracterização de compostos antioxidantes em grãos de diferentes cultivares de cevada (Hordeum vulgare L.). 2009. 108f. Dissertação (Mestrado em Ciência e Tecnologia dos Alimentos) - Curso de Pós-Graduação em Ciência e Tecnologia dos Alimentos, Universidade Federal de Santa Maria, RS. Disponível em: <http://cascavel.cpd.ufsm.br/tede/tde_busca/ arquivo.php? $\operatorname{cod}$ Arquivo $=2383>$.

CARVALHO, J.C.T. et al. Compostos fenólicos simples e heterosídicos. In: SIMÕES, C.M.O. et al. (Orgs). Farmacognosia: da planta ao medicamento. Porto Alegre/Florianópolis: UFRGS/ UFSC, 2004. Cap. 20, p.519-535.

CHRISTIE, P.J. et al. Impact of low-temperature stress on general phenylpropanoid and anthocyanin pathways - enhancement of transcript abundance and anthocyanin pigmentation in maize seedlings. Planta, v.194, n.4, p.541-549, 1994. Disponível em: $<$ http://link.springer.com/article/10.1007\%2FBF00714468\#>. Acesso em: 25 nov. 2008. doi: 10.1007/BF00714468.

DEGÁSPARI, C.H.; WASZCZYNSKYJ, N. Propriedades antioxidantes de compostos fenólicos. Acadêmica, v.5, n.1, p.3340, 2004. Disponível em: <http://www.springerlink.com/content/ v5p3r7w027q60678/fulltext.pdf?page $=1>$. Acesso em: 12 jan. 2009. doi: $10.1007 / \mathrm{BF} 00714468$

DUDT, J.F.; SHURE, D.J. The influence of light and nutrients on foliar phenolics and insect herbivory. Ecology, v.75, n.1, p.86 98, 1994. Disponível em: <http://www.jstor.org/stable/1939385>. Acesso em: 25 nov. 2008.

EMBRAPA TRIGO DE PASSO FUNDO. Rio Grande do Sul (2008). Disponível em: <www.cnpt.embrapa.br/:pesquisa/ agromet/app/principal/agromet.php>. Acesso em: 10 nov. 2008.

GODOY, C.V. SASM - Agri: sistema para análise e separação de médias em experimentos agrícolas pelos métodos Scott-Knott,
Tukey e Duncan. Revista Brasileira de Agrocomputação, v.1, n.2, p.18-24, 2001.

GOUPY, P. et al. Antioxidant composition and activity of barley Hordeum vulgare and malt extracts and isolated phenolics compounds. Journal of the Science of Food and Agriculture, v.79, n.12, p.1625-1634, 1999.

GRACE, S.C.; LOGAN, B.A. Energy dissipation and radical scavenging by the plant phenylpropanoid pathway. Philosophical Transactions of the Royal Society B: Biological Sciences, v.355, n.1402, p.1499-1510, 2000. Disponível em: <http://www3. interscience.wiley.com/cgi-bin/fulltext/119116265/PDFSTART>. Acesso em: 12 jan. 2009. doi: 10.1046/j.1365-3040.1998.00282.x.

GRAY D.E. et al. Acute drought stress and plant age effects on alkamide and phenolic acid content in purple coneflower roots. Planta Medica, v.69, n.3, p.50-55, 2003. Disponível em: <http:// www.ncbi.nlm.nih.gov/pubmed/12567279>. Acesso em: 12 jan. 2009 .

JEONG, S.T. et al. Effects of plant hormones and shading on the accumulation of anthocyanins and the expression of anthocyanin biosynthetic genes in grape berry skins. Plant Science, v.167, n.2, p.247-252, 2004. Disponível em: <http://dx.doi.org/10.1016/j. plantsci.2004.03.021>. Acesso em: 12 jan. 2009.

KNEKT, P. et al. Flavonoid intake and risk of chronic diseases. American Journal of Clinical Nutrition, v.76, n.3, p.560-568, 2002. Disponível em: <http://ajcn.nutrition.org/content/76/3/560. full.pdf>. Acesso em: 12 jan. 2009.

MAILLARD, M.N.; BERSET, C. Evolution of antioxidant activity during kilning: role of insoluble bound phenolic acids of barley and malt. Journal of Agricultural and Food Chemistry, v.43, n.7, p.1789-1793, 1995. Disponível em: <http://pubs.acs.

Ciência Rural, v.43, n.9, set, 2013. 
org/doi/abs/10.1021/jf00055a008>. Acesso em: 25 nov. 2008. doi: $10.1021 / \mathrm{jf00055a008}$.

MCMURROUGH, I. et al. Effect of the removal of sensitive proteins and proanthocyanidins on the colloidal stability of lager beer. Journal of the American Society of Brewing Chemists, v.50, n.2, p.67-76, 1992.

NACZK, M.; SHAHIDI, F. Extraction and analysis of phenolics in food. Journal of Chromatography A, v.1054, n.1-2, p.95-111, 2004. Disponível em: <http://www.sciencedirect.com/science/ article/pii/S0021967304014098>. Acesso em: 12 jan. 2009. doi: 10.1016/j.chroma.2004.08.059.

RODRIGUES, H.G. et al. Suplementação nutricional com antioxidantes naturais: efeito da rutina na concentração de colesterol-HDL. Revista de Nutrição, v.6, n.3, p.315-320, 2003. Disponível em: <http://www.scielo.br/scielo.php?script=sci_artte $\mathrm{xt \& pid}=\mathrm{S} 1415-52732003000300009>$. Acesso em: 25 nov. 2008. doi: http://dx.doi.org/10.1590/S1415-52732003000300009.

SANTOS, M.D.; BLATT, C.T.T. Teor de flavonoides e fenóis totais em folhas de Pyrostegia venusta Miers. de mata e de cerrado. Revista Brasileira de Botânica, v.21, n.2, p.135-140, 1998. Disponível em: <http://www.scielo.br/scielo.php?pid=S0100-
$84041998000200004 \&$ script $=$ sci_arttext $>$. Acesso em: 25 nov. 2008. doi: http://dx.doi.org/10.1590/S0100-84041998000200004.

SHAHIDI, F.; NACZK, M. Phenolics in food and nutraceuticals. Boca Ratón: CRC, 2003. 576p.

SOARES, S.E. Ácidos fenólicos como antioxidantes. Revista de Nutrição, v.15, n.1, p.71-81, 2002. Disponível em: <http://www. scielo.br/scielo.php?pid=S1415-52732002000100008\&script $=$ sci arttext>. Acesso em: 25 nov. 2008. doi: http://dx.doi.org/10.1590/ S1415-52732002000100008.

SOUSA, C.M.M. et al. Fenóis totais e atividade antioxidante de cinco plantas medicinais. Química Nova, v.30, n.2, p.351-355, 2007. <http:// www.scielo.br/scielo.php?pid $=$ s0100-40422007000200021\&script $=$ sci arttext>. Acesso em: 12 jan. 2009. doi: http://dx.doi.org/10.1590/S010040422007000200021

TATTINI, M. et al. Differential accumulation of flavonoids and hydroxycinnamates in leaves of Ligustrum vulgare under excess light and drought stress. New Phytologisty, v.163, n.3, p.547-561, 2004. Disponível em: <http://onlinelibrary.wiley.com/doi/10.1111/ j.1469-8137.2004.01126.x/full >. Acesso em: 25 nov. 2008. doi: 10.1111/j.1469-8137.2004.01126.x.

WATERMAN, P.G.; MOLE, S. Analysis of phenolic plant metabolites. Oxford: Blackwell Scientific Publications, 1994. 248p. 